\title{
Brasil: a luta dos povos indígenas pelos direitos socioambientais e socioculturais
}

Cristiane Gomes Julião²

A história do Brasil para com os povos indígenas é muito triste. É carregada de violências, genocídio, espoliação de terras, grilagem de terras, devastação ambiental, cultural e tradicional. Expressões como silvícolas, ingênuos, selvagens, preguiçosos, sujos e que "falava com demônios porque não falavam o português" são alguns termos empregados aos povos indígenas como forma de condicionar a uma subalternidade e justificar os atos de violências que sofriam.

As frentes de expansão para conhecimento e exploração da vastidão territorial também tinha a missão de "amansá-los"; a igreja, veio com o discurso para dar alma e catequisar. $O$ direito de viver conforme suas crenças e tradições foi sucumbido e a terra já não mais Ihes pertencia... a história é longa e dolorida..., todavia, infelizmente, muita coisa não ficou na história, ainda são realidades indígena no Brasil de hoje.

Para falar sobre direitos socioambientais e socioculturais dos povos indígenas do Brasil, é preciso buscar os elementos que construíram a nossa imagem - do índio - perante o Estado e o Estado perante o índio. E nessa discussão, as categorias que mais se destacam são as questões territoriais e ambientais; a que mais se choca, como é relativo alguns entendimentos sobre se relacionar e se envolver com o meio em que vivemos que podem ser descritas de cinco formas, partindo da

1 Texto apresentado no Colóquio Internacional "A luta pelos Direitos Socioambientais: Brasil e Canadá em Solidariedade". Sherbrooke, 21 de outubro de 2017.

2 Povo indígena Pankararu. Articulação dos Povos Indígenas do Brasil (APIB) 
perspectiva indígena, ou seja, como é diferente o jeito que nós indígenas percebemos a terra e procuramos dialogar sobre política indigenista.

Primeiro: A nossa relação com a terra, não é e jamais será de exploração. A natureza tem seu tempo e a gente aprende a esperar com ela e por ela, porque é dela que revigoramos nossa espiritualidade, nossos alimentos, nosso cotidiano salutar, nossa educação, nossa manutenção social, cultural e tradicional. Ao nosso olhar, meio ambiente não se restringe a mato e bicho no sentido restrito, porque nós também somos parte. Notadamente, o valor que nós povos indígenas damos a terra é imensurável e quanto mais estiver intacta, melhor para nós e para todos. Nesse sentido, defender nossos territórios, é defender o equilíbrio dos ecossistemas, é proporcionar qualidade do ar, é contribuir para que não falte água, é doar sabedoria e saúde com as demais espécies de vida da fauna e da flora que ajudam na cura de muitos males, é com-partilhar culturas com saberes e fazeres diversos que se somam.

Segundo: Enquanto se considerar a regularização territorial indígena como um entrave político econômico para o país, o Estado brasileiro não vai respeitar o nosso direito de ter nossas terras demarcadas, homologadas e desintrusadas conforme estabelecem os marcos regulatórios que o próprio Estado brasileiro promulgou. Essa dicotomia se estende a legislação ambiental, que requer também proteção e impõe regras importantes para a salvaguarda do meio ambiente em função da exploração econômica desordenada, que, de certa forma, também impede a expansão econômica do e no Brasil. Por estas razões, as transformações de comunidades que durante séculos controlaram seus próprios meios de produção econômica, cultural e política, ainda se encontram em situações de dependência e exploração em razão da manutenção hegemônica de classes sociais dominantes pelo poder, pela coerção e pela politicagem em detrimento dessas assimilações forçadas nos diversos povos indígenas do Brasil. No Brasil, o dado oficial ainda de 2010, é de que somos 305 povos, falantes de 274 línguas indígenas, mas os números são maiores se considerarmos os povos isolados. E da mesma forma que é importante a regularização dos 
territórios indígenas, é a manutenção da legislação ambiental, ambos, em defesa do meio ambiente natural.

Terceiro: A presunção da tutela que incide nos espaços estatais como forma de manter o controle sociocultural e socioambiental de povos e comunidades indígenas, através do assistencialismo, cooptação, clientelismo e representatividade. Eu chamo de tutela contemporânea, referindo-me a temporalidade como percebo a tutela hoje em dia, e não exatamente tratar de falar como foi ou como se deu, mas como está. Via de regra, a tutela contemporânea ainda imprime a ideia de nossa incapacidade relativa, e até mesmo de nossa capacidade civil, o que em certa medida incide no desconhecimento do pensamento indígena. A tutela contemporânea pressupõe o falso poder de decisão que somos levados a crer que temos quando a presença indígena como servidores do Estado, não fazem mais que cumprir o que o Estado define, limita e condiciona contradizendo com os usos, costumes e tradições dessa diversidade indígena. Evidentemente, não é só o Estado que usa a tutela contemporânea, muitas organizações não governamentais também usam desse recurso para se aproximar e implementar seus projetos particulares sem que exatamente sejam projetos pensados pelas comunidades ou povos indígenas.

Mas, é importante salientar que a tutela foi pensada para povos indígenas com essa perspectiva de controle. Poderia dizer, como uma versão mais perversa ainda do que foi definido o biopoder ou a biopolítica por Foucault (1978). Se analisarmos os índices de genocídio indígena em pelo menos cinco escalas como: a) antes da instituição legal da tutela; b) a partir da tutela instituída ainda no século XVII (Lei de Liberdade dos Índios, de 06 de junho de 1775); c) a criação dos órgãos indigenistas, inicialmente o Serviço de Proteção ao Índios e Localização dos Trabalhadores Nacionais (SPILTN) em 1910, depois, Serviço de Proteção ao Índio (SPI) em 1918, por último e até hoje, a Fundação Nacional do Índio (FUNAI) em 1967; d) promulgação do Estatuto do Índio (Lei n 6.001, de 19 de dezembro de 1973); e, e) a promulgação da última Constituição Federal (05 de outubro de 1988), veremos os altos índices de dizimação nesse período de "proteção" estatal.

Como bem disse Souza Lima (2015), 
A virada do século XIX para o XX colocava para a classe dominante brasileira, de base eminentemente agrária e por tradição escravista, alguns desafios à manutenção de sua hegemonia sob um novo quadro histórico, caracterizado por mudanças importantes que se implantaram em ritmos e tempos distintos. Dentre estas mudanças, três das mais significativas foram: 1. o término jurídico da escravidão e a necessidade de instauração de uma ordem baseada na liberdade, ainda assim mantendo controle sobre o acesso a terra e sobre a força de trabalho de estratos sociais hierarquicamente inferiores da população, em especial os libertos e seus descendentes; 2. a necessidade de construção efetiva de um aparato administrativo de Estado, com o fim do Real Padroado, logo, do papel de "unidades administrativas mínimas", desempenhado por longo tempo pelas paróquias (com a paralela redefinição ou o surgimento de unidades administrativas propriamente eclesiásticas sobre certos segmentos sociais); 3 . a redefinição dos modos de se imaginar e de se pertencer a uma comunidade política nacional sob um regime republicano federativo. (Souza Lima, 21015).

Lembrando que a tutela do SPI aos povos indígenas até a década de 1960 foi o segundo pior momento de extermínio. O documento mais emblemático é indubitavelmente o Relatório Figueiredo. Um relatório composto de 20 volumes, com 4.942 laudas e mais 06 volumes anexos com 550 páginas, produzido em 1967 pelo procurador Jader de Figueiredo Correa a pedido do Ministro do Interior Brasileiro, Afonso Augusto de Albuquerque Lima. Nele, o procurador descreve violentas práticas por latifundiários brasileiros e funcionários do SPI contra os índios ao longo das décadas de 1940, 1950 e 1960, declarando o quanto ficou "surpreso com a totalidade dos crimes praticados contra a coisa pública e contra a pessoa, a honra e o patrimônio do índio brasileiro [...] a geral corrupção e a anarquia total imperantes no SPI em toda sua área, como também, através dos tempos." (Figueiredo, 1976: 4911). Fato é que

o índio, razão de ser do SPI, tornou-se vítima de verdadeiros celerados, que the imperam um regime de escravidão e the ne- 
garam um mínimo de condição de vida compatível com a dignidade da pessoa humana.

É espantoso que exista na estrutura administrativa do País repartição que haja a tão baixos padrões de decência. E que haja funcionários públicos, cuja bestialidade tenha atingido tais requintes de perversidade. Venderam-se crianças indefesas para servir aos instintos de indivíduos desumanos. Torturas contra crianças e adultos, em monstruosos e lentos suplícios, a título de ministrar justiça (...). (Jader Figueiredo, 1967. p 4912).

O Estatuto do Índio segue o mesmo conceito do Código Civil Brasileiro de 1916 e tem como objetivo "regular a situação jurídica dos índios e das comunidades indígenas, com o propósito de preservar a sua cultura e integrá-los, progressiva e harmonicamente, à comunhão nacional", mas, forçando os critérios de qualificação de indianidade, conforme estabelece o artigo $4^{\circ}$ da Lei $n^{\circ}$ 6001/1973. Nesta mesma lei, o artigo 19 estabelece parâmetros de regularização territorial. Então, pelo menos, desde 1973 o Estado brasileiro determinou que em cinco anos todas as terras indígenas deveriam estar demarcadas (pelo menos aquelas), mas não foi feita muita coisa. Aliás, desde 1978 (cinco anos após o prazo estabelecido) não temos visto muitos avanços nesse sentido. Se nossos argumentos na defesa de nossos territórios evidenciam a premente necessidade vital da biodiversidade, então muda-se a legislação ambiental para facilitar os grandes empreendimentos e o agronegócio que tem sido o carro-chefe desse silencioso e mascarado massacre nacional.

Quarto: Proposituras legislativas contra os direitos socioambientais e socioculturais dos povos indígenas. Na perspectiva indígena, compreendemos direitos socioambientais como sendo a convivência com e entre vários espaços, independentemente se na aldeia, no território e/ ou para além destes; socioculturais, a percepção da convivência com e entre vários saberes/fazeres dos diferentes públicos etários, independentemente se na aldeia, no território e/ou para além destes, por isso lutar pelo território contempla um guarda-chuva de direitos como saúde, educação, segurança, alimentação, saberes/fazeres tradicionais, moradia, manutenção das culturas para as presentes e futuras gerações etc. 
A regulamentação do direito à terra, ou paralelamente esses direitos chamados na linguagem constitucional de direitos sociais, criou a expectativa do respeito e da segurança a partir do Estado brasileiro desencadeando para outros setores e outras instituições. Com a promulgação da Constituição Federal em 1988 e de marcos internacionais que o Brasil ratificou que incidem sobre direitos dos povos indígenas, configurou um novo tempo ao direito de viver conforme nossas crenças e tradições e o direito de existir como todo e qualquer ser humano, inclusive, porque como donos de nossos territórios, os grandes projetos de empreendimentos econômicos (estatais ou não) teriam que ser "repensados", caso passasse dentro ou próximo às terras indígenas. A esse entendimento sobressaltam duas situações: o direito de consulta livre, prévia e informada assegurado aos povos indígenas; e as propostas de mudanças na legislação contra os direitos dos povos indígenas pelo Governo brasileiro como, por exemplo, a Portaria $n^{\circ}$ 303, de 16 de julho de 2012 (dispõe sobre as salvaguardas institucionais às terras indígenas conforme entendimento fixado pelo Supremo Tribunal Federal na Petição 3.388 RR - dezenove condicionantes), bem como pelo Congresso Nacional, sobretudo a bancada BBB (boi, bala e bíblia) com propostas como o Projeto de Lei - PL no 1.610/1996 (sobre mineração), da Proposta de emenda Constitucional - PEC n 215-A/2000 (várias mudanças no artigo 231), o Projeto de Lei Parlamentar - PLP n 227/2012 (regulamenta o $\S 6^{\circ}$ do art. 231, da Constituição Federal de 1988 definindo os bens de relevante interesse público da União para fins de demarcação de Terras Indígenas e o Projeto de Lei - PL n 490/2007 (propõe a revogação do Decreto $\left.n^{\circ} 1.775 / 96\right)$, sem contar o lado perverso da Lei 13.123/2015 que o governo chama de "nova lei da biodiversidade".

Quinto: o protagonismo indígena. De certa forma, o Estatuto do Índio impulsionou a articulação e mobilização nacional dos povos indígenas em unificar a luta pelo direito de existir e de viver, e para isso, é fundamental nossos territórios e o equilíbrio ambiental. Assim sendo, ainda na década de 1970, começa a se consolidar essa comunhão indígena com a criação da União das Nações Indígenas (UNI), entendendo que todos os direitos indígenas incidem sobre a regularização de nossos territórios e do equilíbrio ambiental (educação, saúde, conhecimentos 
tradicionais, soberania e segurança alimentar, ecossistemas, ritual...). A UNI foi importantíssima na defesa desses direitos que na década de 1980 ficou conhecida como Movimento Constituinte, movimento fundamental na consolidação dos artigos 231 e 232 na nova Constituição Federal, promulgada em 05 de outubro de 1988.

Atualmente, consolidamos a Articulação dos Povos e Indígenas do Brasil, a APIB, organização indígena de âmbito nacional congregando as maiores organizações indígenas regionais do país: a Coordenação das Organizações Indígenas da Amazônia Brasileira (COIAB), a Articulação dos Povos e Organizações Indígenas do Nordeste, Minas Gerais e Espírito Santo (APOINME), a Articulação dos Povos Indígenas do Sul (ARPINSUL), a Articulação dos Povos Indígenas do Sudeste (ARPINSUDESTE), a Organização Guarani Aty-Guassu e o Conselho Terena. A APIB tem sede na capital federal e funciona com a participação conjunta de lideranças indígenas indicadas por suas organizações regionais a fim de buscar garantir a participação indígenas nos diversos debates políticos-desenvolvimentistas-econômicos, na defesa dos direitos de gênero e gerações indígenas, na luta pelo território e na organização de mobilizações nacionais como o Acampamento Terra Livre (ATL) que acontece anualmente desde 2004.

Expostos esses cinco pontos, em função da falta de compromisso do Estado brasileiro para com os povos indígenas sobre a regularização territorial, a violência acirra a cada dia. São constantes as violações e violências. Os casos mais dolorosos são dos povos Guarani (Kaiowá, Mbyai e Nhadeva) no estado do Mato Grosso do Sul e Santa Catarina. Ou casos recentes como do povo Gamela no estado do Maranhão, e do bebê indígena Kaingang degolado nos braços da mãe na rodoviária de Santa Catarina, entre muitos que acontecem e que a mídia aberta não divulga. Outras situações de violências constantes são dos povos indígenas do Nordeste, parece que carregamos o fardo de sermos negados, invisibilizados e marginalizados.

Outras formas de olhar a luta pelos direitos socioambientais e socioculturais no Brasil se dão, principalmente sobre o reconhecimento, regulamentação e implementação de direitos, não só nacionais, mas internacionalmente, com participação ou à revelia dos povos indíge- 
nas (fiz uma pesquisa em que descobri que o Brasil é signatário de 102 instrumentos internacionais, e destes, 34 incide sobre a questão indígena). A questão da legalidade não pode estar sempre posta como hierarquia maior em detrimento da legitimidade. Minha utopia é acreditar que legítimo seja um direito que independe do que está posto na lei, e legal o que a lei expressa sem necessariamente considerar a legitimidade da coisa, porém, há de se considerar que comumente se postule lei e legitimidade como sendo coisa igual, aonde uma, ora substitui a outra, ora legitima a outra. Mesmo que consideremos que qualquer ação é um ato político, portanto legal e legítimo.

Todavia, existem duas premissas que as defino como princípio e por esta razão é que suponho incidir na eficácia do propósito: o princípio da intenção e o princípio da interpretação. Tanto a política como as leis são formuladas, acionadas e executadas norteadas por estes princípios - "lei é interpretação e não deixa de fazer política". E a política está na organização social de cada segmento e na relação de cada segmento ainda que, inerente a estas, esteja um conjunto de regras que as defina e/ou direcionem ao "bom convívio" desse(s) grupo(s) social(is) como os códigos de conduta subjetivos que não estão necessariamente decretados em algo mais formal - os acordos, as negociações, as tradições jurídico-sociais próprias.

Por fim, deixo meu apelo:

Quando pensarmos em direitos socioambientais e socioculturais, pensemos no respeito e na construção das relações com todas as formas de vida em todos os espaços físicos e de saberes, porque nós não somos donos da terra, ela é nossa dona, somos apenas mais um ser vivo que a compõe, e com todo respeito e afeto que tenho as todas as nações indígenas do Brasil, peço o apoio e uma atenção especial, se for possível, aos povos indígenas do Nordeste brasileiro e ao bioma Caatinga. Para muito além do que se propaga de tórrido, muito pior é a total ausência política. Nos ajudem a ajudar nosso rio Opará (rio dos currais ou rio São Francisco); nos ajudem a nos manter vivos em vida, e não apenas na história.

Muito obrigada!! 